\title{
Real-time audiovisual feedback system in a physician-staffed helicopter emergency medical service in Finland: the quality results and barriers to implementation
}

\author{
Marko Sainio ${ }^{1 *}$, Antti Kämäräinen ${ }^{1,2}$, Heini Huhtala ${ }^{3}$, Petri Aaltonen ${ }^{4}$, Jyrki Tenhunen ${ }^{1,5}$, Klaus T Olkkola ${ }^{4}$
} and Sanna Hoppu, ${ }^{1,2}$

\begin{abstract}
Objectives: To evaluate the quality of cardiopulmonary resuscitation (CPR) in a physician staffed helicopter emergency medical service (HEMS) using a monitor-defibrillator with a quality analysis feature. As a post hoc analysis, the potential barriers to implementation were surveyed.

Methods: The quality of CPR performed by the HEMS from November 2008 to April 2010 was analysed. To evaluate the implementation rate of quality analysis, the HEMS database was screened for all cardiac arrest missions during the study period. As a consequence of the observed low implementation rate, a survey was sent to physicians working in the HEMS to evaluate the possible reasons for not utilizing the automated quality analysis feature.

Results: During the study period, the quality analysis was used for 52 out of 187 patients (28\%). In these cases the mean compression depth was $<40 \mathrm{~mm}$ in $46 \%$ and $<50 \mathrm{~mm}$ in $96 \%$ of the 1-min analysis intervals, but otherwise CPR quality corresponded with the 2005 resuscitation guidelines. In particular, the no-flow fraction was remarkably low $0.10(0.07,0.16)$. The most common reasons for not using quality-controlled CPR were that the device itself was not taken to the scene, or not applied to the patient, because another EMS unit was already treating the patient with another defibrillator.
\end{abstract}

Conclusions: When quality-controlled CPR technology was used, the indicators of good quality CPR as described in the 2005 resuscitation guidelines were mostly achieved albeit with sufficient compression depth. The use of the well-described technology in improving patient care was low. Wider implementation of the automated quality control and feedback feature in defibrillators could further improve the quality of CPR on the field.

Trial registration: ClinicalTrials.gov (NCT00951704)

Keywords: CPR, Quality, Resuscitation, Cardiac arrest, Pre-hospital, HEMS

\section{Introduction}

The quality of cardiopulmonary resuscitation (CPR), as quantified by CPR quality variables such as chest compression depth, compression rate, full chest recoil and minimal interruptions in CPR are correlated with the likelihood of return of spontaneous circulation (ROSC) after cardiac arrest [1-5]. This is plausible since

\footnotetext{
* Correspondence: marko.sainio@fimnet.fi

${ }^{1}$ Department of Intensive Care Medicine, Tampere University Hospital and University of Tampere, PO Box 2000, Tampere Fl-33521, Finland

Full list of author information is available at the end of the article
}

low-quality CPR has been shown to be associated with several negative haemodynamic effects [6-8]. Although we are aware of the importance of CPR quality to survival after cardiac arrest, recent reports have described significant deficiencies in the quality of CPR provided by health care personnel both in hospital [9] and prehospital environment [10].

Modern defibrillator technology enables continuous monitoring of CPR quality using a sternal accelerometer/ force transducer and impedance changes across the defibrillation electrodes which facilitates automated real-time

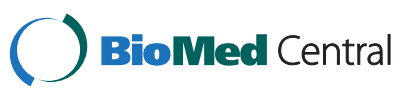


feedback. Although the use of a prototype of such a defibrillator has increased the quality of CPR during prehospital resuscitation [11] this technology is not routinely used. An additional potential benefit for the quality of CPR comes through the possibility for postevent debriefing $[12,13]$.

The purpose of this study was to evaluate CPR quality in a physician staffed helicopter emergency medical service (HEMS) in Southwest Finland. We also analysed the implementation rate of real- time audio-visual feedback device in CPR and tried to ascertain why it was not used in all resuscitation attempts.

\section{Material and methods}

The data on pre-hospital cardiac arrests treated by the HEMS of the Turku area in Southern Finland were collected prospectively between 1 November 2008 and 30 April 2010. The HEMS serves approximately 630000 inhabitants including the city of Turku with a population of 175.000 . The majority of the HEMS physicians are specialists in anaesthesiology and intensive care medicine. In addition to the HEMS, the EMS system includes first responding units (FRU) and basic life support (BLS) units staffed with firemen-emergency medical technicians (EMT) and paramedic staffed advanced life support (ALS) units. Alongside a FRU and the nearest BLS or ALS unit, the HEMS is always dispatched to high-risk medical emergencies such as suspected cardiac arrest. In most emergencies the HEMS usually arrives few minutes after the land crew. Successfully resuscitated patients with return of spontaneous circulation (ROSC) are transported to the Turku University Hospital, which is a tertiary referral centre providing therapeutic hypothermia and percutaneous coronary intervention for cardiac arrest victims when indicated.

The study protocol was approved by the Institutional Review Board of the Tampere University Hospital and registered in clinicaltrials.gov (NCT00951704). All patients $\geq 18$ years of age suffering from sudden prehospital cardiac arrest regardless of the initial rhythm or presumed aetiology were considered eligible to the study. The ethics committee waived the written informed consent procedure due to the observational nature of the study and because we were including only adult patients.

In addition to common emergency medical equipment, the HEMS unit was equipped with a HeartStart MRx defibrillator with Q-CPR ${ }^{\mathrm{mx}}$ option, jointly designed by Philips Health Care (Andover, MA, USA) and Laerdal Medical AS (Stavanger, Norway). All physicians received extra training in the use of the real time audio-visual feedback device (Q-CPR) with repeated instructions and reminders to use of the quality analysis feature. During the study period, resuscitation followed the 2005 ILCOR guidelines [14].
The physicians were trained to ensure that the oval shaped compression sensor (sternal accelerometer/force transducer) was attached to the patient's chest at the scene and CPR was to be continued according to the feedback from the Q-CPR. Attaching the sensor on the chest is quick and has no impact on hands-off time (time without chest compression). Furthermore one can assume that it does not confound the teamwork needed during CPR. However, the decision whether or not to use the Q-CPR feature during resuscitation attempts was left at the physician's discretion.

During each resuscitation the device recorded compression-to-compression depth, compression rate, compression-to-decompression duty cycle, incomplete chest compression release, hands-off (no-flow) time, pre- and post-shock pauses and ventilation rate. As indicators of quality, compression depth, rate and release and ventilation rate were monitored during CPR with automated real-time audiovisual feedback. During the study period CPR goals were a compression rate of 90 to $120 / \mathrm{min}$, depth of 38 to $51 \mathrm{~mm}$ and a ventilation rate of 8 to $12 / \mathrm{min}$.

The detailed information on the performance during the resuscitation were processed and analysed with Q-CPR Review software v2.1.1.0. (Laerdal Medical AS, Stavanger, Norway). Uniform guidelines for reporting CPR quality established by an international consensus working-group were used [15].

In the primary analysis each resuscitation attempt was divided into 1-min intervals for evaluation, and measured variables included overall average compression depth $(\mathrm{mm})$, compression rate $(\mathrm{CC} / \mathrm{min})$, and compression count (actual number of compressions delivered per minute), no flow time (NFT, time without chest compressions) per 1-min intervals, likewise the no flow fraction (NFF, the fraction of time with no compressions during cardiac arrest). Further, percentages of intervals with an average depth $<40 \mathrm{~mm},<50 \mathrm{~mm}$ or average rates $<90$ or $>120 \mathrm{~min}^{-1}$ were also determined. Incomplete chest release percentage was calculated from compressions delivered per minute, from total number of the episode compressions and from total number of all compressions. Pre- and post-shock pauses (s) were analysed. Restoration of spontaneous circulation (ROSC), 24-h survival, survival to hospital discharge and neurological status six months after discharge were also analysed. In addition, we calculated the number of cases where the Q-CPR feature was used.

In the secondary analysis we retrieved the data on all cardiac arrests (resuscitation attempts with or without the real time audio-visual feedback feature) and assessed the basic characteristics and outcome details according to the Utstein style [16]. Neurological status at the discharge was assessed by reviewing of the medical records 
and classified by degree of reported disability and discharge destination.

The descriptive survey was done by questionnaire to all HEMS physicians and the aim was to assess the reasons for the low rate of Q-CPR feature use. The questionnaire included the following questions: 1. "Have you attended resuscitation scenarios while working in the HEMS?" A: Yes or No, 2. "Was the Q-CPR feature used in all cases?" A: Yes or No, 3. "If the Q-CPR feature was not used, please specify the reason." A: a. "Q-CPR device was not carry to the scene", b) "device was not used, because another EMS unit was already treating the patient with another defibrillator", c) "it is unnecessary to use the real time audio-visual feedback feature in every cardiac arrest patient", d) "another reason, what?"

Statistical analyses were performed with SPSS for windows (SPSS version 19.0, Chicago, IL). Data are presented as numbers and percentages of patients, as median with interquartile range (IQR), or as means and standard deviations (SD) pending the normality of distribution. Differences between groups were analysed using the $X[2]$-test with continuity correction for categorical data and Student's $t$ test or Mann-Whitney $U$ test for continuous data as appropriate.

\section{Results}

During the 18-month study period the HEMS accomplished a total of 5,318 missions. These included 391 cases of cardiac arrest in which either the FRU or the HEMS considered resuscitation. In 338 cases (86\%) the FRU initiated resuscitation at the scene. In 46 (12\%) cases the paramedics considered the attempt futile and the HEMS physicians confirmed this. One patient had a do-not-attempt-resuscitation (DNAR) order and in six cases the data were missing.

At the time of HEMS arrival, the FRU or the paramedics had achieved ROSC in 70 patients. In 81 cases the HEMS physician considered further resuscitation attempts futile. In the final analysis, out of the initial 391 cardiac arrests there were $187(48 \%)$ patients on the HEMS initiated or continued resuscitation. The Utstein style flow chart of core data elements is presented in Figure 1.

Of the 187 patients, quality-controlled CPR was provided in 52 cases $(28 \%)$. The median duration of the

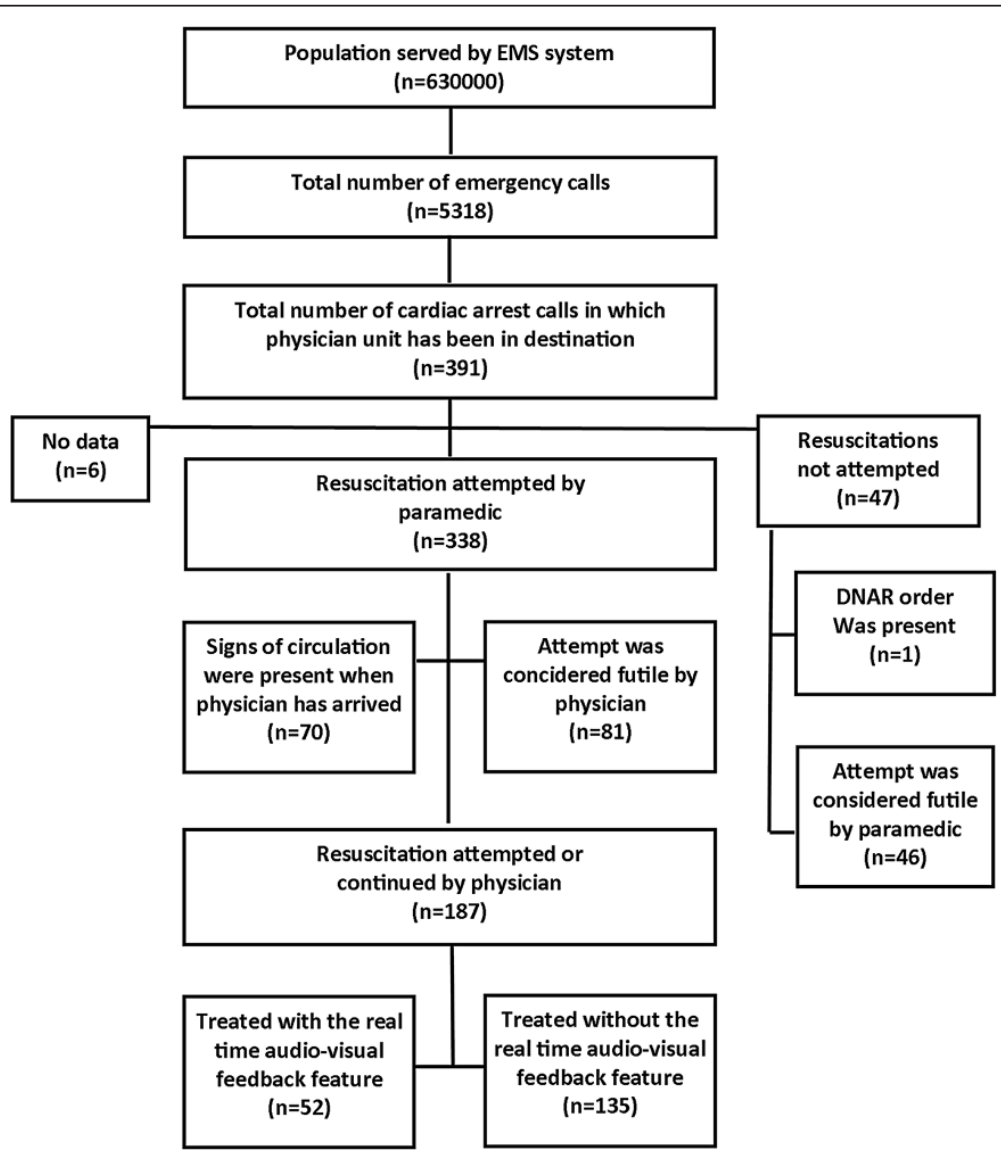

Figure 1 The Utstein style flow chart of core data elements. 
resuscitation with real-time audio-visual feedback feature was $12 \min 6 \mathrm{~s}(7 \mathrm{~min} 48 \mathrm{~s}, 16 \mathrm{~min} 53 \mathrm{~s})$. The mean compression depth was 40 (6) $\mathrm{mm}$ and in $46 \%$ out of the 1 -min intervals compression depth remained $<40 \mathrm{~mm}$. In 20 of the 52 resuscitation attempts the mean compression depth was sufficient $(>40 \mathrm{~mm})$ in $>60 \%$ of the 1-min intervals. The mean compression rate was 108 (10) $\mathrm{min}^{-1}$, with $10 \%$ of all 1 -min intervals with a compression rate $<90$ or $>120 \mathrm{~min}^{-1}$. The median noflow fraction was $0.10(0.07,0.16)$ and the mean no-flow time per 1-min fraction was 7 (9) seconds, resulting in actual compressions delivered per minute at a mean rate of 95 (20) $\mathrm{min}^{-1}$. The median incomplete chest release percentage out of the total number of compressions was $3(1,14) \%$, and the median pre- and post-shock pauses were $9(5,15)$ and $3(2,5)$ s respectively (Table 1$)$.

In the secondary analysis the median HEMS unit response interval to cardiac arrest patients treated with or without the real time audio-visual feedback feature was $12(10,15)$ and $12(10,15) \min (\mathrm{p}=\mathrm{NS})$ respectively. The median delays from HEMS arrival to ROSC achieved with or without the real time audio-visual feedback feature were $12(10,15)$ and $7(5,17)$ min $(p=0.05)$ respectively. Demographic and resuscitation episode characteristics and outcome parameters of the two groups are presented in Table 2.

\section{Survey}

Eight HEMS physicians out of 11 responded to the survey. Six respondents were specialists in anaesthesiology and intensive care medicine, one an attending internist and one a senior resident in anaesthesiology and intensive care. All respondents had attended resuscitation attempts during the study period and used the real time audio-visual feedback feature during resuscitation attempts. All respondents had also attended resuscitation attempts in which the Q-CPR had not been used. The most common reason for not using quality-controlled CPR was failure to carry the Q-CPR device to the scene. Secondly, another EMS unit was in many cases already treating the patient with another defibrillator. All physicians considered it unnecessary to use the real-time

Table 1 Data on quality of cardiopulmonary resuscitation (CPR) treated by physicians with Q-CPR $(\mathbf{n}=\mathbf{5 2})$

\begin{tabular}{|c|c|}
\hline Episode duration, median (IQR), min:s & 12:06 (7:48, 16:53) \\
\hline Total number of compressions, (No.) & 62895 \\
\hline \multicolumn{2}{|l|}{ Compression depth (mm) } \\
\hline Episode mean (SD) & $40(6)$ \\
\hline Fraction of 1-min epochs with compression depth $<40$ mm, No. (\%) & $292 / 629(46)$ \\
\hline Fraction of 1-min epochs with compression depth < 50 mm, No. (\%) & $604 / 629(96)$ \\
\hline Compression depth within recommended (>40 mm) $>60 \%$ of episodes 1-min epochs, No (\%) & 20/52 (39) \\
\hline \multicolumn{2}{|l|}{ Compression rate $\left(\min ^{-1}\right)^{a}$} \\
\hline Episode mean (SD) & $108(10)$ \\
\hline Fraction of minutes with compression rate $<90$ or $>120 \mathrm{~min}^{-1}$, No. (\%) & $60 / 629(10)$ \\
\hline Compressions delivered $\left(\min ^{-1}\right)$, episode mean (SD) ${ }^{\mathrm{b}}$ & $95(20)$ \\
\hline \multicolumn{2}{|l|}{ Compressions with incomplete release ${ }^{c}$} \\
\hline Number of total compressions, No. (\%) & $5158 / 62895(8)$ \\
\hline Percentage of total number of episode compressions, median (IQR) & $3(1,14)$ \\
\hline Incomplete chest release per 1 min segments, median (IQR),\% & $0(0,6)$ \\
\hline Compression as part of duty cycle, episode mean (SD), $\%$ & $43(4)$ \\
\hline \multicolumn{2}{|l|}{ No flow time (pauses) ${ }^{d}$} \\
\hline No-flow fraction, median (IQR) & $0.10(0.07,0.16)$ \\
\hline No flow time per $60 \mathrm{~s}$ fraction, mean (SD), s & $7(9)$ \\
\hline Pre-shock pause, median (IQR) ${ }^{\mathrm{e}}$, s & $9(5,15)$ \\
\hline Post-shock pause, median $(\mathrm{IQR})^{f}, \mathrm{~s}$ & $3(2,5)$ \\
\hline
\end{tabular}

The data are presented as numbers and percentages of patients, as median and $25 \%$ to $75 \%$ interquartile range (IQR), or as means and standard deviations (SD) as appropriate (non-normal or normal distribution respectively).

andicates the rate of compressions when delivered.

$\mathrm{b}$ Indicates the average number of compressions actually given per minute during the resuscitation attempt.

Indicates the incomplete chest wall decompression after chest compression phase.

${ }^{d}$ Indicates the proportion of time without chest compressions during the resuscitation attempt.

endicates the proportion of time during rhythm analyses? without chest compressions before shock.

IIndicates the proportion of time during rhythm analyses? without chest compressions after shock. 
Table 2 Demographics and quality of cardiopulmonary resuscitation (CPR) treated by physicians

\begin{tabular}{l} 
Characteristic \\
\hline Age, mean (SD), y \\
Data not available \\
Male sex, No. (\%) \\
Cardiac aetiology, No. (\%) \\
Location of arrest, No. (\%) \\
Home \\
Public \\
Other \\
Data not available
\end{tabular}

Cardiac arrest witnessed status, No. (\%)

Bystander witnessed
EMS personnel witnessed
Arrest not witnessed
FRU unit:

$\begin{array}{ccc}30(58) & 87(64) & 0.39 \\ 9(17) & 23(17) & 0.97 \\ 13(25) & 25(19) & 0.32\end{array}$

Response interval in all cases,
median (IQR), min
Data not available
Response interval in VFNT
cases, median (IQR), min
Data not available
HEMS unit:

$\begin{array}{ccc}5(2,8) & 6(2,10) & 0.68 \\ 3 & 19 & \\ 6(4,10) & 7(3,10) & 0.73\end{array}$

\begin{tabular}{|c|c|c|c|}
\hline $\begin{array}{l}\text { Responded with helicopter, } \\
\text { No. (\%) }\end{array}$ & $13(25)$ & $45(33)$ & 0.23 \\
\hline $\begin{array}{l}\text { Response interval (all), } \\
\text { median (IQR), min }\end{array}$ & $12(10,15)$ & $12(10,15)$ & 0.58 \\
\hline Data not available (\%) & $3(6)$ & $2(1)$ & \\
\hline $\begin{array}{l}\text { Response interval of } \\
\text { helicopter, median (IQR), min }\end{array}$ & $12(10,16)$ & $17(12,24)$ & 0.22 \\
\hline $\begin{array}{l}\text { Response interval of rapid } \\
\text { response vehicle, median } \\
\text { (IQR), min }\end{array}$ & $12(10,15)$ & $11(9,13)$ & 0.49 \\
\hline \multicolumn{4}{|l|}{ Initial rhythm, No. (\%) } \\
\hline VFNT & $22(42)$ & $38(28)$ & 0.06 \\
\hline Asystole & $12(23)$ & $50(37)$ & 0.07 \\
\hline PEA & $18(35)$ & $44(33)$ & 0.79 \\
\hline Data not available & 0 & 3 & \\
\hline $\begin{array}{l}\text { Time from call to ROSC, } \\
\text { median (IQR), min }\end{array}$ & $26(21,29)$ & $24(15,29)$ & 0.24 \\
\hline $\begin{array}{l}\text { Time from HEMS unit arrival to } \\
\text { ROSC, median (IQR), min }\end{array}$ & $12(10,15)$ & $7(5,17)$ & 0.05 \\
\hline \multicolumn{4}{|l|}{ Patient outcome, No. (\%) } \\
\hline Any ROSC & $28(54)$ & $49(36)$ & 0.03 \\
\hline Primary survival to $\mathrm{ED} / \mathrm{ICU}$ & $22(42)$ & $35(26)$ & 0.03 \\
\hline Alive after 24 hours & $18(35)$ & $29(22)$ & 0.06 \\
\hline
\end{tabular}

Table 2 Demographics and quality of cardiopulmonary resuscitation (CPR) treated by physicians (Continued)

\begin{tabular}{lccc}
\hline $\begin{array}{l}\text { Discharged from hospital } \\
\text { alive }\end{array}$ & $8(15)$ & $22(16)$ & 0.88 \\
Data not available & 0 & 2 & \\
$\begin{array}{l}\text { Neurological outcome at } \\
6 \text { month all patient, No. (\%) }\end{array}$ & & & \\
CPC 1-2 & $8(15)$ & $13(10)$ & 0.26 \\
CPC 3 & 0 & 0 & \\
CPC 4-5 & $44(85)$ & $113(84)$ & 0.87 \\
Data not available & 0 & 9 & \\
\hline
\end{tabular}

Abbreviations: FRU First responding units, HEMS Helicopter emergency medical service, VF, ventricular fibrillation, VT Ventricular tachycardia, PEA Pulseless electrical activity, ROSC Return of spontaneous circulation, ED, Emergency department, ICU, Intensive care unit, $C P C$, Cerebral performance category. The data are presented as numbers and percentages of patients, as median and $25 \%$ to $75 \%$ interquartile range (IQR) or as mean and standard deviation (SD) as appropriate (non-normal or normal distribution respectively).

"The differences between groups were analysed using chi-square test with continuity correction for categorical data and $t$ test or Mann-Whitney test for continuous data as appropriate. No trauma related cardiac arrest patients were enrolled as by chance.

audio-visual feedback feature on every cardiac arrest patient, especially if the response time had been long.

\section{Discussion}

In this study HEMS physicians used the real time audiovisual feedback feature in only $28 \%$ of all resuscitation attempts. When asked, HEMS physicians reported three main reasons for not using the real time audio-visual feedback feature to guide resuscitation in all resuscitation attempts. First, when a primary responding unit had already initiated resuscitation using a defibrillator without the quality analysis feature, it was generally considered unnecessarily burdensome or useless to change the equipment. Second, in some cases the defibrillator with the quality analysis feature had not been brought to the patient at all and third, in few cases the use of the Q-CPR was not considered worthwhile when the arrival of the HEMS was delayed. Regarding the time delays, the median HEMS response interval in all patients treated without Q-CPR was only $12 \mathrm{~min}$ in our study, which contradicts the assumption that long response intervals contraindicated the use of the real-time audiovisual feedback feature. The responses to the survey exemplify attitudes that need to be tackled through training and research.

Recent studies report that real-time feedback devices used during a resuscitation attempt can modify CPR performance and improve adherence to resuscitation guidelines [11,17-22]. This per se is an important goal. Although the main aim in using real time audio-visual feedback is to increase the likelihood of performing $\mathrm{CPR}$ according to the international resuscitation guidelines, 
in this study only 20 cases (38\%) had the mean compression depth within the recommendation of more than $60 \%$ of the 1 -min intervals. In the latest 2010 resuscitation guidelines the target compression depth is at least $50 \mathrm{~mm}$ [23]. Interestingly, the mean compression depth remained $<50 \mathrm{~mm}$ in $96 \%$ of all 1-min intervals in this study. The other quality variables such as mean compression rate, compressions delivered $\mathrm{min}^{-1}$, incomplete chest release and no-flow fraction were mostly within the recommended range. Of note, no flow fraction was very low $0.10(0.07,0.16)$. Two recently published prospective observational cohort studies demonstrated relationship between compression fraction (1- no-flow fraction) and likelihood of ROSC in OCHA patients with confirmed ventricular fibrillation and also patients with not in ventricular fibrillation. High compression fraction was independently predictive of better survival in patients who experience a prehospital ventricular fibrillation/tachycardia cardiac arrest $[3,4]$. However, there is little if any data demonstrating that quality controlled CPR actually improves patient outcome in out of hospital setting $[21,24,25]$. This may be reflected in emergency physicians' attitudes and result in low utilisation of the quality analysis feature. A recently published report by the Resuscitation Outcomes Consortium (ROC) investigators evaluated whether real-time feedback increases the likelihood of ROSC in out-of-hospital setting. The use of real time audio-visual feedback improved the mean compression depth by only $2 \mathrm{~mm}$ (from $37.7 \mathrm{~mm}$ to $39.7 \mathrm{~mm}$ ) and the fraction of the time with active chest compression from $64 \%$ to $66 \%$. The investigators therefore concluded that likelihood of ROSC was not associated with the use real time audio-visual feedback [25]. Stiell et al. demonstrated recently an association between survival and increased compression depth in pre-hospital setting, but also numerous deficiencies in achieving recommended chest compression depth despite having real time audio-visual feedback [5], which concurs with our small-scale study. These studies demonstrate the need to measure chest compression depth routinely during CPR, and it should be noted that real time audio-visual feedback does not by itself guarantee sufficient chest compression depth or low no-flow fraction, and future studies are needed to analyze the impact of the nontechnical skills to the quality of resuscitation attempt.

Studies have shown a delay of over a year in the implementation of resuscitation guidelines in clinical practice $[26,27]$. Bigham et al. interviewed 176 EMS agencies to elicit "what issue, if any, delayed implementation of the guidelines into field practice". In that survey the three main barriers were insufficient training, technical aspects and reluctance to accept new guidelines in clinical practice [28]. A study from Scotland reported that real- time feedback with targeted training improves the quality of pre-hospital resuscitation. Unfortunately, it was underpowered to demonstrate an association, or lack thereof, between improved CPR quality and better outcome [22]. During our study period of 18 months the use of the Q-CPR was rarely deployed despite initial training and repeated instructions and reminders. One explanation could be that the HEMS physicians received no feedback on the quality of the resuscitation attempts during the study period. It has previously been observed that post-event reporting and debriefing have a positive impact on the quality of resuscitation $[17,29]$.

To improve CPR quality by deploying CPR feedback/ prompt devices, it is crucial for emergency physicians and other professionals to understand the operating principle of the equipment. Demonstrating that using Q-CPR technology improves survival will make such technology more readily accepted.

This study has limitations. First, although the initial data collection on the use of Q-CPR was prospective, the final survey on the success rate of the implementation was retrospective and post hoc in nature. Second, due to the low implementation rate the number of cases in which Q-CPR was used remained low. However, the latter limitation seems to reflect the real life obstacle observed in this study, which per se could not be prospectively addressed without risking the Hawthorne effect [30]. Finally, the reader is reminded to bear in mind the low number of patients, observational non-randomized design and in particular the primary rhythm differences between the groups when considering the relevance of the outcome measures in this report. Our primary aim was not to report outcome measurers for the between the groups comparison, rather to describe the overall patient cohort and performance.

The survey responses represent respondents' subjective perceptions in general and the reasons why not using the Q-CPR feature cannot be defined in detail. There may have been cases where the clinical or operative situation did not permit the use of quality analysis, but the study setting allows no in-depth analysis of these situations.

\section{Conclusions}

In the present study, HEMS physicians made little use of a well-described technology with potential for improving patient care. When quality-controlled CPR technology was used, the indicators of good quality CPR were mostly achieved, but compression depth was insufficient. If we want to improve CPR quality via implementation of CPR feedback/prompt devices, it is of utmost importance that HEMS physicians and other professionals understand the operational principle of the equipment. If we can prove that the use Q-CPR technology improves survival, it is not difficult to increase the popularity of such technology. 
Knowledge, training and understanding the purpose of new technology are key elements for successful implementation of new devices and protocols such as quality analysis and feedback during CPR. Further evidence to support the potential benefits of quality analysis during CPR, extensive training of medical professionals and a wider availability of defibrillators with the quality analysis feature could be the means to achieve improved resuscitation quality.

\section{Competing interests}

Dr. Jyrki Tenhunen has been a member of international advisory board for SuPARnostic (Virogates, Copenhagen, Denmark) and is CMO and shareholder in SenSem Technologies Ltd (Tampere, Finland.) and Medieta Ltd (Helsinki, Finland). Dr. Sanna Hoppu has provided paid consultancy for Laerdal Medical Corporation. Laerdal Medical has not funded any part of this study, nor had access to any of the data or partaken in the process of the study. Other authors have no conflicts of interest to declare.

\section{Authors' contributions}

MS had full access to all of the data in the study and takes responsibility for the integrity of the data and the accuracy of the data analysis. Study concept and design: MS, HS, PA. Critical revision of the manuscript for important intellectual content: MS, AK, JT, KTO, SH. Statistical analysis: MS. HH. Analysis and interpretation of data: MS, AK, JT, KTO, SH. All authors read and approved the final manusrcipt.

\section{Acknowledgement}

This study was funded by the Instrumentarium Foundation, Helsinki, Finland, and by the Competitive Research Funding of the Tampere University Hospital (Grant 9 M105). The funding organizations had no involvement in excecution or reporting of the study.

\section{Author details}

${ }^{1}$ Department of Intensive Care Medicine, Tampere University Hospital and University of Tampere, PO Box 2000, Tampere Fl-33521, Finland. '2Department of Emergency Medicine, Tampere University Hospital and University of Tampere, PO Box 2000, Tampere FI-33521, Finland. 3'School of Health Sciences, University of Tampere, Tampere Fl-33014, Finland. ${ }^{4}$ Department of Anaesthesiology, Intensive Care, Emergency Care and Pain Medicine, University of Turku and Turku University Hospital, PO Box 52 (Kiinamyllynkatu 4-8), Turku Fl-20521, Finland. ${ }^{5}$ Department of Surgical Sciences, Anaesthesiology and Intensive Care, Uppsala University, Uppsala SE 751 85, Sweden.

Received: 11 December 2012 Accepted: 23 June 2013

Published: 1 July 2013

\section{References}

1. Eftestø| T, Sunde K, Steen PA: Effects of interrupting precordial compressions on the calculated probability of defibrillation success during Out-of-hospital cardiac arrest. Circulation 2002, 105:2270-2273.

2. Abella BS, Sandbo N, Vassilatos P, Alvarado JP, O'Hearn N, Wigder HN, Hoffman P, Tynus K, Vanden Hoek TL, Becker LB: Chest compression rates during cardiopulmonary resuscitation are suboptimal: a prospective study during in-hospital cardiac arrest. Circulation 2005, 111:428-434.

3. Resuscitation Outcomes Consortium Investigators, Christenson J, Andrusiek D, Everson-Stewart S, Kudenchuk P, Hostler D, Powell J, Callaway CW, Bishop D, Vaillancourt C, Davis D, Aufderheide TP, Idris A, Stouffer JA, Stiell I, Berg R: Chest compression fraction determines survival in patients with Out-of-hospital ventricular fibrillation. Circulation 2009, 120:1241-1247.

4. Resuscitation Outcomes Consortium Investigators, Vaillancourt C, Everson-Stewart S, Christenson J, Andrusiek D, Powell J, Nichol G, Cheskes S, Aufderheide TP, Berg R, Stiell IG: The impact of increased chest compression fraction on return of spontaneous circulation for out-of-hospital cardiac arrest patients not in ventricular fibrillation. Resuscitation 2011, 82:1501-1507.

5. Stiell IG, Brown SP, Christenson J, Cheskes S, Nichol G, Powell J, Bigham B, Morrison LJ, Larsen J, Hess E, Vaillancourt C, Davis DP, Callaway CW, Resuscitation Outcomes Consortium (ROC) Investigators: What is the role of chest compression depth during out-of-hospital cardiac arrest resuscitation. Crit Care Med 2012, 40(4):1192-1198.

6. Berg RA, Sanders AB, Kern KB, Hilwig RW, Heidenreich JW, Porter ME, Ewy GA: Adverse hemodynamic effects of interrupting chest compressions for rescue breathing during cardiopulmonary resuscitation for ventricular fibrillation cardiac arrest. Circulation 2001, 104:2465-2470.

7. Kern KB, Hilwig RW, Berg RA, Sanders AB, Ewy GA: Importance of continuous chest compressions during cardiopulmonary resuscitation: improved outcome during a simulated single lay-rescuer scenario. Circulation 2002, 105:645-649.

8. Yannopoulos D, McKnite S, Aufderheide TP, Sigurdsson G, Pirrallo RG, Benditt D, Lurie KG: Effects of incomplete chest wall decompression during cardiopulmonary resuscitation on coronary and cerebral perfusion pressures in a porcine model of cardiac arrest. Resuscitation 2005, 64:363-372.

9. Abella BS, Alvarado JP, Myklebust H, Edelson DP, Barry A, O'Hearn N, Vanden Hoek TL, Becker LB: Quality of cardiopulmonary resuscitation during in-hospital cardiac arrest. JAMA 2005, 293:305-310.

10. Wik L, Kramer-Johansen J, Myklebust H, Sørebø H, Svensson L, Fellows B, Steen PA: Quality of cardiopulmonary resuscitation during out-of-hospital cardiac arrest. JAMA 2005, 293:299-304.

11. Kramer-Johansen J, Myklebust H, Wik L, Fellows B, Svensson L, Sørebø H, Steen PA: Quality of out-of-hospital cardiopulmonary resuscitation with real time automated feedback: a prospective interventional study. Resuscitation 2006, 71:283-292.

12. Scherer LA, Chang MC, Meredith JW, Battistella FD: Videotape review leads to rapid and sustained learning. Am J Surg 2003, 185(6):516-520.

13. Townsend RN, Clark R, Ramenofsky ML, Diamond DL: ATLS-based videotape trauma resuscitation review: education and outcome. J Trauma 1993 34(1):133-138

14. European Resuscitation Council, Nolan JP, Deakin CD, Soar J, Böttiger BW, Smith G: European resuscitation council guidelines for resuscitation 2005. Section 4. Adult advanced life support. Resuscitation 2005, 67(1):39-86.

15. Kramer-Johansen J, Edelson DP, Losertd H, Köhler K, Abella BS: Uniform reporting of measured quality of cardiopulmonary resuscitation (CPR). Resuscitation 2007, 74:406-417.

16. Jacobs I, Nadkarni V, Bahr J, Berg RA, Billi JE, Bossaert L, Cassan P, Coovadia A, D'Este K, Finn J, Halperin H, Handley A, Herlitz J, Hickey R, Idris A, Kloeck W, Larkin GL, Mancini ME, Mason P, Mears G, Monsieurs K, Montgomery W, Morley P, Nichol G, Nolan J, Okada K, Perlman J, Shuster M, Steen PA, Sterz F, et al: Cardiac arrest and cardiopulmonary resuscitation outcome reports: update and simplification of the Utstein templates for resuscitation registries. A statement for healthcare professionals from a task force of the international liaison committee on resuscitation (American Heart Association, European Resuscitation Council, Australian Resuscitation Council, New Zealand Resuscitation Council, Heart and Stroke Foundation of Canada, InterAmerican Heart Foundation, Resuscitation Council of Southern Africa). Resuscitation 2004, 63:233-249.

17. Edelson DP, Litzinger B, Arora V, Walsh D, Kim S, Lauderdale DS, Vanden Hoek TL, Becker LB, Abella BS: Improving in-hospital cardiac arrest process and outcomes with performance debriefing. Arch Intern Med 2008, 168:1063-1069.

18. Niles D, Nysaether J, Sutton R, Nishisaki A, Abella BS, Arbogast K, Maltese MR, Berg RA, Helfaer M, Nadkarni V: Leaning is common during in-hospital pediatric CPR, and decreased with automated corrective feedback. Resuscitation 2009, 80:553-557.

19. Chiang WC, Chen WJ, Chen SY, Ko PC, Lin CH, Tsai MS, Chang WT, Chen SC, Tsan CY, Ma MH: Better adherence to the guidelines during cardiopulmonary resuscitation through the provision of audio-prompts. Resuscitation 2005, 64:297-301.

20. Abella BS, Edelson DP, Kim S, Retzer E, Myklebust H, Barry AM, O'Hearn N, Hoek TL, Becker LB: CPR quality improvement during in-hospital cardiac arrest using a real-time audiovisual feedback system. Resuscitation 2007, 73:54-61.

21. Yeung J, Meeks R, Edelson D, Gao F, Soar J, Perkins GD: The use of CPR feedback/prompt devices during training and CPR performance: $A$ systematic review. Resuscitation 2009, 80:743-751.

22. Lyon RM, Clarke S, Milligan D, Clegg GR: Resuscitation feedback and targeted education improves quality of pre-hospital resuscitation in Scotland. Resuscitation 2012, 83:70-75.

23. Nolan JP, Soar J, Zideman DA, Biarent D, Bossaert LL, Deakin C, Koster RW, Wyllie J, Böttiger B: European resuscitation council guidelines for 
resuscitation 2010 section 1. Executive summary. Resuscitation 2010, 8:1219-1276.

24. Olasveengen TM, Tomlinson A-E, Wik L, Sunde K, Steen PA, Myklebust $H$, Kramer-Johansen J: A failed attempt to improve quality of out-of-hospital CPR through performance evaluation. Prehosp Emerg Care 2007, 11:427-433.

25. Resuscitation Outcomes Consortium Investigators, Hostler D, Everson-Stewart S, Rea TD, Stiell IG, Callaway CW, Kudenchuk PJ, Sears GK, Emerson SS, Nichol G: Effect of real-time feedback during cardiopulmonary resuscitation outside hospital: prospective, cluster randomised trial. BMJ 2011, 342:d512.

26. Berdowski J, Schmohl A, Tijssen JGP, Koster RW: Time needed for a regional emergency medical system to implement resuscitation guidelines 2005-the Netherlands experience. Resuscitation 2009, 80:1336-1341.

27. ROC Investigators, Bigham BL, Koprowicz K, Aufderheide TP, Davis DP Donn S, Powell J, Suffoletto B, Nafziger S, Stouffer J, Idris A, Morrison LJ: Delayed prehospital implementation of the 2005 American Heart Association Guidelines for cardiopulmonary resuscitation and emergency cardiac care. Prehosp Emerg Care 2010, 14:355-360.

28. ROC Investigators, Bigham BL, Aufderheide TP, Davis DP, Powell J, Donn S, Suffoletto B, Nafziger S, Stouffer J, Morrison LJ: Knowledge translation in emergency medical services: a qualitative survey of barriers to guideline implementation. Resuscitation 2010, 81:836-840.

29. Lukas RP, Gräsner JT, Seewald S, Lefering R, Weber TP, Van Aken H, Fischer M, Bohn A: Chest compression quality management and return of spontaneous circulation: a matched-pair registry study. Resuscitation 2012, 83:1212-1218.

30. Wickström G, Bendix T: The "Hawthorne effect"-what did the original Hawthorne studies actually show. Scand J Work Environ Health 2000, 26:267-363.

doi:10.1186/1757-7241-21-50

Cite this article as: Sainio et al:: Real-time audiovisual feedback system in a physician-staffed helicopter emergency medical service in Finland: the quality results and barriers to implementation. Scandinavian Journal of Trauma, Resuscitation and Emergency Medicine 2013 21:50.

\section{Submit your next manuscript to BioMed Central and take full advantage of:}

- Convenient online submission

- Thorough peer review

- No space constraints or color figure charges

- Immediate publication on acceptance

- Inclusion in PubMed, CAS, Scopus and Google Scholar

- Research which is freely available for redistribution 